\title{
Crafting a Business Mindset: A Theoretical Model Identifying Influencers of Professional Reciprocity
}

\author{
Salvador G. Villegas \\ Northern State University \\ Robert A. Lloyd \\ Fort Hays State University
}

The study of reciprocity within inter-organizational exchanges has been a widely investigated subject matter since the concept was first declared a universal personal norm by Gouldner (1960). In business practice, many networking organizations thrive on creating an environment where professionals can pass leads, referrals, and clients to one another for mutual gain (BNI, 2017). Though the power of professional reciprocity is actualized in industry, this study seeks to identify specific factors that influence a professional's sentiment of reciprocity. This quantitative research investigates influencers both on the positive (rewarding) and negative (punishing) sides of the reciprocity spectrum. Study findings identified that industry type, professional experience, and gender act as factors that directly act as influencers of negative reciprocity. In contrast, a professional's education level is shown to influence positive reciprocity directly. These findings have aided in creating the Reciprocal Influencers Model and posits that professional reciprocity should also be considered a universal business norm.

Keywords: reciprocity, professionalism, business networking, business management, influence, social capital

\section{INTRODUCTION}

Treat others the way that you want to be treated. This renowned idiom has been taught for centuries from the time of the Middle Kingdom of Ancient Egypt (2040-1782 BCE) as seen in the narrative of the Eloquent Peasant, which states, "A good action comes back to its place of yesterday. Such is the precept, 'Do to the doer so as to cause him to do"' (Gardiner, 1923, p. 7). In the Holy Bible, this social concept is mentioned in Matthew 7:12 and Luke 6:31 with the phrase "Do to others whatever you would have them do to you" (The New American Bible, Revised Edition). Modern research demonstrates the significance of reciprocity within social structures as all humans are considered reciprocal in nature (homo reciprocus) (Becker, 1956). When Becker (1956) made this argument, he did so without ever defining the term reciprocity. For generations and still today, this concept is taught as the Golden Rule. What is considered a universal personal norm (Gouldner, 1960), understanding those factors that influence reciprocal sentiment is crucial in comprehending the complexity of this multi-directional construct. In business practice, reciprocity has produced a direct economic benefit for individuals, organizations, and communities that choose to engage in exchanges with one another (Kolm, 1994). Reciprocity in action has been the 
cornerstone of many business networking success stories. For example, in 2017, upwards of 220,000 Business Networking International (BNI) members passed business referrals to one or another for more than $\$ 13.6$ billion (BNI, 2017). This business bases its networking model on the philosophy that those who give business referrals will gain economic success through reciprocity (BNI, 2017). Some business leaders go so far as to argue that professionals cannot have a relationship nor success without business reciprocity (Llopis, 2016). Further exploration of this concept is essential to both business theory and practice.

Through a quantitative study discovering the relationship between generational cohort and reciprocal sentiment, Villegas (2020) identified that generation is not correlated to positive reciprocity, in other words rewarding kindness with kindness. It was discovered however that there are statistically significant differences between the reciprocal sentiment of professionals from the Baby Boomer generation when compared to those in the Millennial generation. This research has also identified several other significant factors that directly impact the sentiment of reciprocity (Kolm, 1994) for professionals. This paper examines these additional findings and develops a fluid theoretical understanding of factors directly influencing reciprocity within a professional context. These findings help to answer the question, what factors influence a professional's sentiment of reciprocity?

\section{LITERATURE REVIEW}

The scope of this research covers several theoretical constructs, including the norm of generalized reciprocity (positive \& negative), attributes of organizational reciprocity (inter-organizational trust, relational social capital, and competitive advantage). Past literature provides valuable insight as to the differences of opinion when creating theoretical frameworks on reciprocity. The Norm of Reciprocity (Gouldner, 1960) establishes reciprocity as a personal norm; however, this behavioral value has since evolved to be considered a social norm (Perugini et al., 2002). Within an organizational/professional setting, many researchers have argued that reciprocal actions are the guiding force for inter-organizational reciprocal trust activities (Adler \& Kwon, 2002; Barney \& Hansen, 1994; Goldstein et al., 2011; Oliveria, 2013).

It is with this understanding that personal sentiment informs organizational behavior that encapsulates this research. Corporate operations, organizational structure, and individual influence within inter-firm exchanges all impact how reciprocal actions occur. Reciprocity itself requires varied cognitive mechanisms and behavioral strategies when implemented (Schweinfurth \& Call, 2019). In keeping within the scope of this research, the succinct definition for reciprocity in this study is:

Reciprocity is the intrinsic motivation to respond to the behavior of a related person. The concept of reciprocity is divided into two opposing aspects, namely positive reciprocity, and negative reciprocity: positive (negative) reciprocity is the intention of rewarding (punishing) those who have been kind (mean) to us. (Caliendo, Fossen, \& Kritikos, 2012, p.3)

This definition is consistent with the understanding that reciprocity is manifested in social exchange theory, which rewards mutual transactions and interactions within societal relationships (Cropanzano \& Mitchell, 2005).

Much research currently exists on personal and organizational reciprocity, including reciprocity in professional friendships (Olk \& Gibbons, 2010), strategic appointment reciprocity (Carpenter \& Westphal, 2001), reciprocity in interpersonal and organizational citizenship behavior (Bowler \& Brass, 2006), and reciprocity based on workplace communication issues created by relational misperceptions (Byron \& Landis, 2020). Many of these types of studies are grounded in theoretical constructs, including balance theory (Heider, 1958), social capital theory (Adler \& Kwon, 2002; Nahapiet \& Ghoshal, 1998), and trust

(Barney \& Hansen, 1994; Vaux Halliday, 2003). However, most significant research on this subject matter only identifies key results of reciprocal activity within professional/organizational interactions without identifying the key factors that influence a professional mindset. A glaring gap exists in the literature 
relating to those factors that influence a professional's perception of reciprocity; this research may fill this void and add to the body of knowledge on this subject matter. This study advances past research findings in a manner that looks specifically at reciprocity through a professional lens to determine which demographic characteristics and experiential attributes correlate to an individual's sentiment of professional reciprocal behavior.

\section{METHODOLOGY}

Reciprocity researchers have demonstrated value in employing both qualitative and quantitative research methods on this subject. Those that have taken a correlational approach used surveys as the method of data analysis (Belmi \& Pfeffer, 2015; Chollet et al., 2014; Falk \& Fischbacher, 2006; Goldstein et al., 2011). This research's impetus aims to gain a specific and measurable understanding of how professionals perceive reciprocity, and a quantitative study is the prescribed methodology. This research has been designed to identify any critical correlations, similarities, and differences between different demographic attributes/characteristics their sentiment towards professional reciprocity.

\section{Research Questions}

The research question for this study is:

\section{R1: What factors influence a professional's sentiment of reciprocity?}

The primary hypothesis for this study seeks to determine if measurable differences can be identified in the results derived from this research:

$\boldsymbol{H}_{1}$ : There are clear and identifiable characteristics that influence how professionals perceive reciprocity.

$\boldsymbol{H}_{0}$ : There are not clear and identifiable characteristics that influence how professionals perceive reciprocity.

In this research, the respective demographic and experiential attributes act as independent variables, whereas the sentiment of reciprocity (both negative and positive) acts as the dependent directional variables. Differences are identified with both sentiments of negative reciprocity and positive reciprocity.

\section{Participants}

Participants for this survey are a sample of active business professionals primarily located within the Pacific Northwest. Participants may also include professionals active in business networking forums (service clubs, fraternal organizations, trade groups, etc.) and those who are not. All survey invitations were delivered via a digital platform only, and no paper option was available. Each professional invited to participate is a legal adult, eighteen (18) years old or older. The invitation was distributed to professionals regardless of age, industry type, and experience during the Summer of 2019.

\section{Instrument}

As used in previous research, a validated survey was used (Dohmen et al., 2009; Richter et al., 2013) based on the reciprocity questions found in the 2005 Wave of SOEP questionnaire. Within the administration of this survey, collected information included both demographic and experiential answers from this group of professionals. The instrument used a six-question survey offering a seven-point Likert scale to determine a professional's feelings towards the concept of reciprocity. In this survey,
$1=$ Does not apply to me at all
$2=$ Mostly does not apply to me
$5=$ Slightly applies to me
$3=$ Slightly does not apply to me
$6=$ Mostly applies to me
$4=$ Neutral
$7=$ Applies to me perfectly 
As previous researchers have argued that the personal sentiments of reciprocity are what builds the foundations of organizational trust (Adler \& Kwon, 2002; Barney \& Hansen, 1994; Goldstein et al., 2011; Oliveria, 2013), the responses of these professionals provide insight to the understanding of reciprocity in both an organizational \& professional perspective.

\section{Procedure}

Survey participants were sent a digital hyperlink to the survey via an electronic invitation (e-mail or direct message). All surveys were conducted through SurveyMonkey, a reputable survey website. The identity of any respondents and their corresponding answers were kept completely anonymous, even to researchers. Pertinent demographic information such as respondent age, gender, educational level, industry, years of professional business experience, and organization type (for-profit, not-for-profit) was collected. All professional respondents who work in for-profit, not-for-profit, governmental agencies, and retired professionals were granted access to complete this survey. Only complete surveys were analyzed, while incomplete or partial surveys were excluded.

\section{RESEARCH FINDINGS}

All data were recorded and analyzed using SPSS 22.0. Several analyses were performed with the data to measure for accuracy and reliability. Data analysis of each variable identified the following correlations (Table 1).

TABLE 1

PEARSON R VARIABLE CORRELATION MATRIX - POSITIVE RECIPROCITY

\begin{tabular}{lllllllll} 
& & 1 & 2 & 3 & 4 & 5 & 6 & 7 \\
\hline 1 & Industry & 1.00 & & & & & & \\
2 & Experience & -0.13 & 1.00 & & & & & \\
3 & Generation & -0.09 & $-.45^{* *}$ & 1.00 & & & & \\
4 & Gender & -0.09 & 0.09 & -0.11 & 1.00 & & & \\
5 & Education & 0.07 & 0.05 & -0.06 & $.26^{* *}$ & 1.00 & & \\
6 & Evolution & 0.03 & -0.12 & 0.17 & -0.12 & -0.10 & 1.00 & \\
7 & Positive Rec & -0.14 & 0.01 & 0.05 & -0.11 & $-.33^{* *}$ & -0.16 & 1.00 \\
\hline
\end{tabular}

**. Correlation is significant at the 0.01 level (2-tailed).

A Spearman's Rho analysis (Table 2) identifies the correlational relationships between the negative reciprocity dependent variable and each of the independent variables within this study (industry, experience, generational cohort, gender, education level, and reciprocal evolution). The data produced several findings related to both the positive and negative reciprocity variables. The Pearson $\mathrm{R}$ correlational analysis found that a professional's education level statistically influences their positive reciprocity sentiment. Though interrelated to generational demographics, the factors of education, industry type, workforce experience, and gender demonstrated statistically significant correlations to reciprocal sentiments. 
TABLE 2

SPEARMAN'S RHO VARIABLE CORRELATION MATRIX

\begin{tabular}{lllllllll} 
& & 1 & 2 & 3 & 4 & 5 & 6 & 7 \\
\hline 1 & Industry & 1.00 & & & & & & \\
2 & Experience & -0.14 & 1.00 & & & & & \\
3 & Generation & -0.05 & $-.40^{* *}$ & 1.00 & & & & \\
4 & Gender & -0.11 & 0.07 & -0.12 & 1.00 & & & \\
5 & Education & 0.12 & 0.04 & -0.10 & $.27^{* *}$ & 1.00 & & \\
6 & Evolution & 0.02 & -0.11 & $.22^{*}$ & -0.12 & -0.11 & 1.00 & \\
7 & Negative Rec & $-0.19^{*}$ & $-.26^{* *}$ & $.21^{*}$ & $.24^{* *}$ & 0.15 & -0.01 & 1.00 \\
\hline
\end{tabular}

*. Correlation is significant at the 0.05 level (2-tailed).

**. Correlation is significant at the 0.01 level (2-tailed)

\section{Reciprocal Correlations}

Initial correlational analysis of the data showed two separate yet different findings when comparing both positive and negative reciprocity. Positive reciprocity is not correlated with generational identity, whereas negative reciprocity is statistically correlated with generational identity. Additionally, when the other independent demographic variables were analyzed with both types of reciprocity, several variables show a statistically significant correlation:

- The Pearson R correlation analysis shows that positive reciprocity correlates to the highest level of education completed at a statistically significant 0.01 level (2-tailed) with an $r=-0.33$. A coefficient of determination showed an $r^{2}=.1089$, showing a small effect size. This identifies that $10.8 \%$ of the variance of either variable is shared with the other.

- Spearman's Rho correlation analysis confirms that negative reciprocity correlates to years in industry at a statistically significant 0.05 level (2-tailed) with a $\rho=-0.19$. The $\rho=0.19$ shows that this correlation results in a small effect size.

- The Spearman's Rho correlation analysis confirms that negative reciprocity correlates to years of industry experience at a statistically significant 0.01 level (2-tailed) with a $\rho=-0.26$. The $\rho$ $=0.26$ shows that this correlation results in a small effect size.

- Spearman's Rho correlation analysis confirms that negative reciprocity correlates to gender identity at a statistically significant 0.01 level (2-tailed) with a $\rho=0.24$. The $\rho=0.24$ shows that this correlation results in a small effect size.

All survey data was further tested using an appropriate ANOVA with a post-hoc Tukey HSD test to explore any differences between the groups within each of these variables.

\section{Education Level}

Further exploration of each independent variable (Industry, Experience, Generation, Gender, Education, and Evolution) was analyzed with an ANOVA, including a post-hoc Tukey HSD test to determine any other measurable differences between groups. The ANOVA analyses revealed that there was only one independent variable that affected the sentiment of positive reciprocity. This investigation produced a statistically significant difference between groups when comparing the highest level of education completed on positive reciprocity at $p=0.01$ with $F(4,114)=3.82$ (Table 3 ). An eta squared test showed an $\eta^{2}=.118$, resulting in a medium effect size for this relationship. This identifies that $11.8 \%$ of the variability in positive reciprocity can be accounted for by variability in the highest level of educated completed. 
TABLE 3

POSITIVE RECIPROCITY \& HIGHEST LEVEL OF EDUCATION COMPLETED ANOVA

\begin{tabular}{|l|l|l|l|l|l|}
\hline & Sum of Squares & Df & Mean Square & F & Sig. \\
\hline Between Groups & 7.168 & 4 & 1.79 & 3.82 & .01 \\
Within Groups & 53.529 & 114 & 0.47 & & \\
Total & 60.697 & 118 & & & \\
\hline
\end{tabular}

The post-hoc survey analysis shows that there is a statistically significant difference $(p<0.05)$ between those respondents whose highest level of education was high school and those with a bachelor's degree at $p=0.03$ (Table 4). Similarly, there was a significant statistical difference at the $p<0.05$ level between those respondents who graduated from high school and those who have earned a doctorate at a significance level of $p=0.02$.

TABLE 4

POST-HOC TUKEY HSD: EDUCATION LEVEL ANOVA

\begin{tabular}{|c|c|c|c|c|}
\hline \multicolumn{2}{|c|}{ (I) Highest Level of Education } & Mean Difference (I-J) & Std. Error & Sig. \\
\hline \multirow{4}{*}{$\begin{array}{l}\text { Graduated from } \\
\text { High School }\end{array}$} & Associates & .00 & .25 & 1.00 \\
\hline & Bachelors & $.49^{*}$ & .16 & .03 \\
\hline & Masters & .31 & .19 & .48 \\
\hline & Doctorate & $.77^{*}$ & .25 & .02 \\
\hline \multirow[t]{4}{*}{ Associate degree } & High School & .00 & .25 & 1.00 \\
\hline & Bachelors & .49 & .24 & .25 \\
\hline & Masters & .31 & .26 & .75 \\
\hline & Doctorate & .77 & .31 & .10 \\
\hline \multirow[t]{4}{*}{ Bachelor's Degree } & High School & $-.49^{*}$ & .16 & .03 \\
\hline & Associates & -.49 & .24 & .25 \\
\hline & Masters & -.17 & .17 & .85 \\
\hline & Doctorate & .28 & .24 & .76 \\
\hline \multirow[t]{4}{*}{ Master's degree } & High School & -.31 & .19 & .48 \\
\hline & Associates & -.31 & .26 & .75 \\
\hline & Bachelors & .17 & .17 & .85 \\
\hline & Doctorate & .46 & .26 & .40 \\
\hline \multirow[t]{4}{*}{ Doctorate Degree } & High School & $-.77^{*}$ & .25 & .02 \\
\hline & Associates & -.77 & .31 & .10 \\
\hline & Bachelors & -.28 & .24 & .76 \\
\hline & Masters & -.46 & .26 & .40 \\
\hline
\end{tabular}

*. The mean difference is significant at the 0.05 level. 


\section{Experience Level}

As part of the demographic data collected, survey respondents were asked to provide their years of experience within their fields. This variable did not correlate to positive reciprocity; however, there was indeed a statistically significant correlation (at the $\mathrm{p}<0.05$ level) with negative reciprocity (Table 2 ). The ANOVA and post-hoc test, between experience level on negative reciprocity was reinforced at a statistically significant $\mathrm{p}=0.046$ with $\mathrm{F}(4,117)=2.501$ (Table 5).

TABLE 5

YEARS OF PROFESSIONAL EXPERIENCE ANOVA - NEGATIVE RECIPROCITY

\begin{tabular}{|l|l|l|l|l|l|}
\hline & Sum of Squares & Df & Mean Square & F & Sig. \\
\hline Between Groups & 12.922 & 4 & 3.230 & 2.501 & .046 \\
Within Groups & 151.138 & 117 & 1.292 & & \\
Total & 164.059 & 122 & & & \\
\hline
\end{tabular}

An eta squared test showed an $\eta^{2}=.078$, resulting in a medium effect size for this relationship. This shows that $7.8 \%$ of the negative reciprocity variable's variability can be accounted for by a respondent's years of professional experience. Surprisingly, the Tukey HSD test results on these variables did not identify any statistically significant differences between the groups at the $p<0.05$ level.

\section{DISCUSSION}

All participants completed this survey out of their own free will as there were no incentives offered to complete the questionnaire. Demographic information, including age, gender, industry type, industry experience, and the highest level of education completed, was also collected in this study. Based on the definition of Caliendo, et al. (2012), reciprocity is the inherent personal motivation to respond to the conduct of another person. Caliendo, et al. (2012) further argues that this concept is divided into two distinct and opposing aspects, where positive reciprocity is the intention of rewarding those who have been kind to us, and negative reciprocity is the intention of punishing those who have been mean to us (p. 3). Identifying reciprocity in terms of both positive and negative measures coincides with the grounded theory on this subject matter.

This study found that the positive reciprocity variable is significantly correlated with survey participants' education level. These findings contrast those of previous researchers who argue that demographics and education have little impact on reciprocity amongst professional adults (Olk \& Gibbons, 2010). within Additionally, negative reciprocity has been found to correlate with the industry type, tenure, or years of experience that professionals have completed within their industry and gender. Every independent variable collected (generational cohort, gender, industry type, industry experience, the highest level of education completed, and evolution of reciprocal sentiment) was analyzed using an ANOVA calculation with positive and negative reciprocity (separately). Only education level and positive reciprocity showed a statistically significant relationship to one another. After reviewing the negative reciprocity ANOVA results with each independent variable, only experience level identified a statistically significant relationship. Based on this experiment and analysis, the primary hypothesis $H_{l}$ is supported and has statistically significant correlations between professional reciprocity and the unique characteristics that influence this sentiment and subsequent behavior. Upon analyzing this data, the null hypothesis $\left(\mathrm{H}_{0}\right)$ is rejected and the alternative hypothesis $\left(\mathrm{H}_{1}\right)$ is accepted. 


\section{Implications on Theory}

Theoretically, several important discoveries have emerged from this research as several key variables were shown to correlate to the directional attribute of reciprocity when testing the negative reciprocity variable. Industry type, years of experience, and gender identity all displayed a significant relationship to negative reciprocity, creating a working theoretical model.

\section{Education Level}

The data analysis identified that the highest level of education completed correlated to an individual's feelings toward positive reciprocity. Through the ANOVA analysis and subsequent post-hoc test, it became clear that there were statistical differences in reciprocity between those who have only completed a high school education compared to those with either a bachelor's or doctorate. There could be several reasons why this significance has been identified, including the possibility of self-regulating for long-term goals instead of short-term, post-secondary lessons on reciprocity, economic factors, and educational access. There has been minimal research on this topic in a quick exploration of education level's interrelatedness to reciprocal attitudes. Further investigation of this correlation and differences between groups could be a possible direction for future researchers.

\section{Experience Level}

The level of professional experience and its influence on negative reciprocity was an unanticipated association. Based on this study, there is a negative correlation between the experience and negative reciprocity variables, deducing that the amount of experience someone has in an industry will limit their vengefulness or willingness to retaliate when they feel that they have been harmed. Seasoned professionals are more willing to let harmful behavior subside without an equal response. However, those with less experience seemed poised to seek retribution when they feel that they have been harmed. Much as with education level, there has been minimal research on how professional experience/tenure affects how someone feels about reciprocity. Future researchers should further explore this topic to seek out a more robust theoretical understanding of this correlation.

\section{Theoretical Model}

This study has identified key factors influencing a professional's sentimentality regarding reciprocity's positive and negative directions. Some of these factors only impact one of the directions of the reciprocity but not the other. Within the bounds of this research, demographic data was collected to identify which, if any, of these attributes significantly influence professional feelings of reciprocity. Based on statistical analysis, several vital demographic characteristics influence reciprocal sentiment among professionals (Figure 1). This proposed model, the Reciprocal Influencers Model, identifies that professional reciprocal sentiment comprises specific influencers that impact an individual's feelings towards negative and positive reciprocity. 
FIGURE 1

\section{RECIPROCAL INFLUENCERS MODEL}

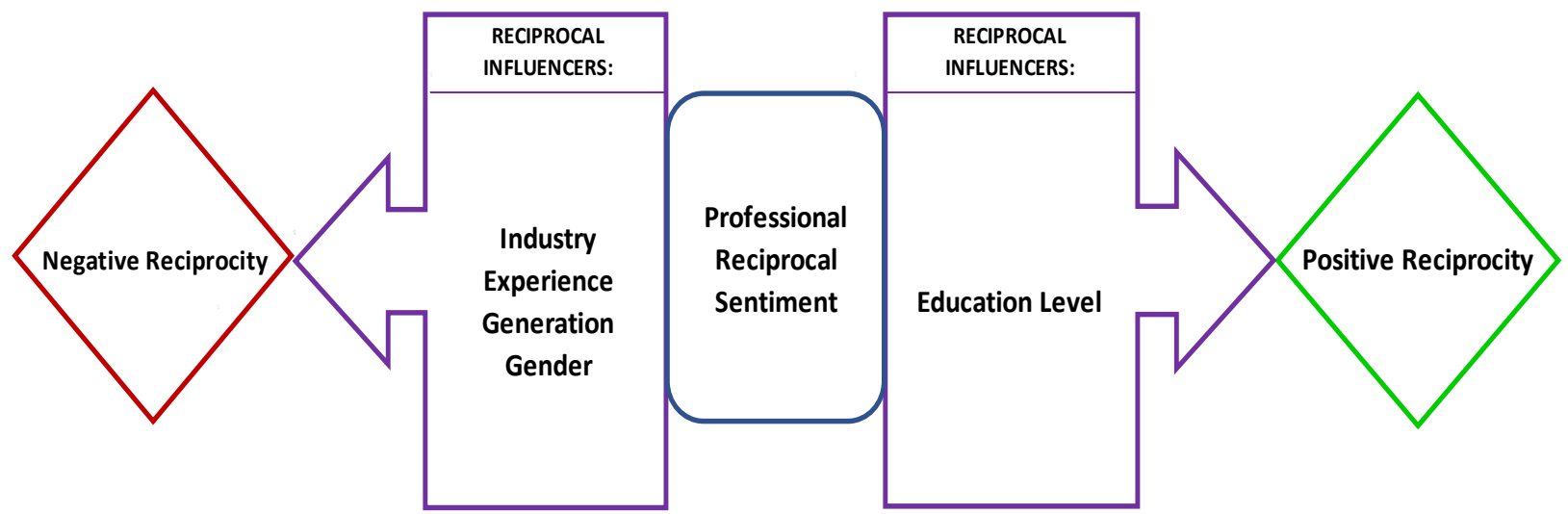

This proposed model is not explicitly limited to only the demographic data collected in this study, as there could be many other personal and professional attributes that shape a professional's reciprocal sentiment. Whereas much of the past research on reciprocity has focused the relationship with other traits like trust (Maximiano, 2012; Sabel, 1993), career (Nieß, 2014), satisfaction (Budria \& Ferrer-i-Carbonell, 2012), relational misperceptions (Byron \& Landis, 2020), entrepreneurship (Caliendo et al., 2012), locus of control (Heineck \& Anger, 2008), and ethics (Tangpong et al., 2016), the findings in this study discover those areas of a professional's life that shape/influence their unique holistic reciprocal sentiment.

This study's findings identify industry, professional experience, and gender as factors that directly aid in crafting a business mindset by acting as influencers of negative reciprocity. These influential factors are not alone, as extant research on this topic has discovered other factors which directly influence how professionals feel about negative reciprocity. These factors include inclination toward anger (Eisenberger et al., 2004), professional culture (Kalyanpur \& Harry, 1999), political affiliation \& religion within defined groups (Fitzgerald \& Wickwire, 2012). Each of these variables has been shown to directly correlate to the formation of negative reciprocal sentiment in a professional's life.

FIGURE 2

\section{RECIPROCAL INFLUENCERS MODEL - NEGATIVE RECIPROCITY}

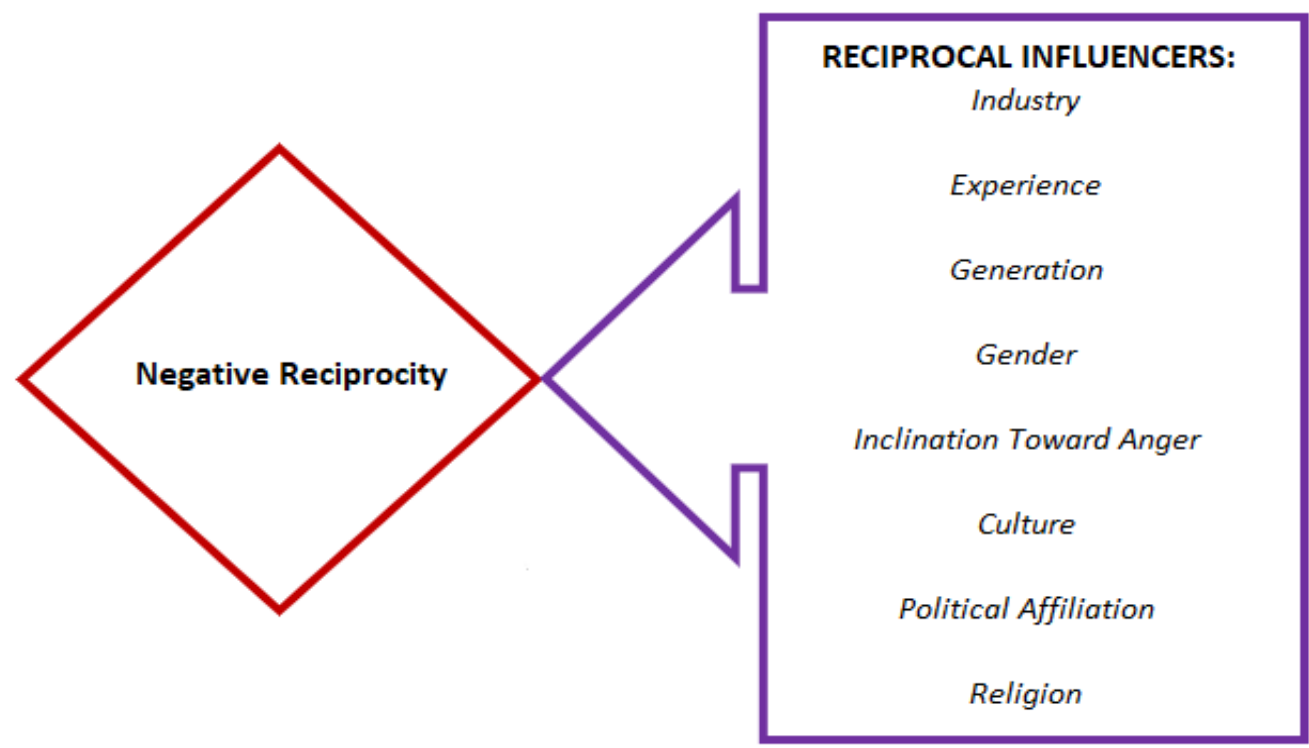


In analyzing positive reciprocity within the context of a professional mindset, this study's findings have shown that education level is the only correlated attribute out of the ones tested. Further research on this topic has shown that positive reciprocity is influenced by other facts such as structure-based interactivity (Sanchez-Franco \& Roldán, 2015), family \& culture (Parette, 2005), shared schemata (Long \& Mathews, 2011), obligation (Knight et al., 2016), and group religion/political affiliation (Fitzgerald \& Wickwire, 2012). These demographic factors play an active role in crafting a business mindset to influence reciprocal sentimentality uniquely.

\section{FIGURE 3 \\ RECIPROCAL INFLUENCERS MODEL - POSITIVE RECIPROCITY}

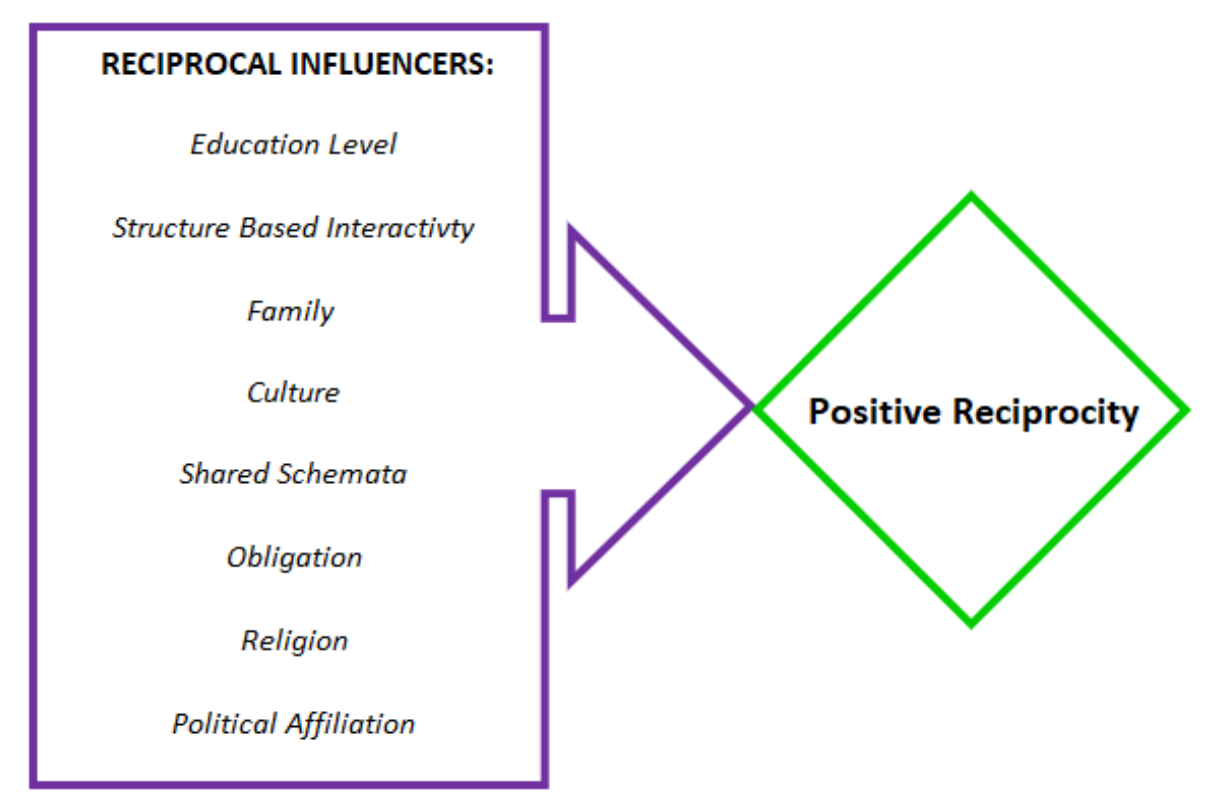

\section{Implications to Practice}

The findings relating to education level and positive reciprocity have shown that professionals who have earned degrees (bachelors and doctorate) tend to practice positive reciprocity than their high school educated counterparts. Hiring educated professionals seems the appropriate choice for those industries that heavily rely on reciprocal exchanges to foster growth/revenue (for-profit, not-for-profit). Educated professionals seem to understand that to gain in business, a professional must be willing to give in order to succeed. These professionals do not see rewarding others as altruism per se, but rather a karmic action that will be met with an equally beneficial reaction. Hiring an educated professional could exponentially increase reciprocal opportunities for hiring managers in sales, marketing, professional services, and nonprofit donation acquisition.

Understanding the personal attributes of those showing a greater inclination towards entertaining negative reciprocal activity (vengeance) is equally essential in business practices. It may be beneficial for a professional to avoid networking with or establish relationships with individuals who hold extreme political views, known anger issues, exclusionary religious ideas, or even limited experience in their field. All these identifying factors have been shown to influence negative reciprocity. Granted, some positions such as law enforcement, commission-based sales, lawyers, or even professional coaches with a solid willingness to react in an unkind or aggressive manner can benefit the organization. However, as with most research, these are generalities, and individuals should be judged on their character and merit. 


\section{Study Limitations}

Although this analysis's results have demonstrated their theoretical and industry importance, a few identifiable factors may limit this study. These limitations include:

- Complexity of survey instrument - This validated survey on reciprocity comprised six questions/items, including only two dependent variables. Possibly, a longer questionnaire could have yielded different results. Regardless this questionnaire and corresponding analysis have been able to provide valuable findings.

- Method of survey administration - This survey was solely available through an online portal, possibly affecting those professionals' participation with limited online access.

- Geographic location of survey participants -All respondents were professionals primarily located in a suburban community within the Pacific Northwest. It is unclear if potential cultural, geographic, and diversity biases/differences in this geographic region could have affected the outcome.

- Voluntary response bias - All participation was completed voluntarily. This unforced involvement adds to the potential for response bias.

This study has allowed for insight into understanding how professionals uniquely feel about rewarding and punishing those who interact similarly. Regardless of these potential study limitations, the value derived through this research study adds value to the practice management, the psychological understandings of reciprocity, and the factors that influence the formation of a business mindset regarding professional interactions.

\section{Suggestions for Future Research}

This topic has several facets that can be further explored to gain more knowledge on reciprocity. First and foremost, identifying influencers that shape professional reciprocal sentiment is paramount to expanding the Reciprocal Influencers Model. Knowing which factors shape how reciprocity shapes workforce interactions influences theory, but many business implications require further investigation. A secondary suggestion for future research is to test this research's findings and statistical replicability by administering this survey to a much broader population or in a different geographic area. Further investigation into this topic could expand the sample to include larger cities to determine differences in urban/suburban/rural understandings into reciprocity. If tested internationally, this methodology and model could identify a cultural difference between professionals, especially regarding the ideas of collectivism vs. individualism. It is unclear if this will result in significant findings that differ from those found here or if future research will substantiate and validate what has been calculated within this survey's bounds.

Future research could potentially use this study's finding as the basis for a deeper investigation to see if the sentimentality of professional reciprocity is different across several types of industries and organizational positions. Future studies could identify if managers and non-management employees shared similar ideas on reciprocal behavior or if statistical differences exist. As this research sought to identify the sentimentality of professional reciprocity by intentionally having respondents answer from a professional perspective, it would be prudent for future researchers to seek a different viewpoint and ask respondents to answer from a purely personal perspective. It would then be interesting to compare any statistically significant differences between personal and professional sentimentality towards reciprocity.

\section{CONCLUSION}

Regardless of a professional's generational identity, reciprocity is a factor that influences personal and professional (social) interactions/behavior (Mahmoodi et al., 2018). When professionals interact to benefit or harm one another, reciprocity will continue to act as society's currency (Haidt \& Graham, 2007). In the spirit of professional reciprocal relationships, while professionals continue to network with one another beneficially, there is a perception of balance between interactions. The correlational relationships identified

within this research support the idea that social networking is tied directly through reciprocation based on 
interpersonal citizenship behavior, as postulated by Boulder \& Brass (2006). While some personal characteristics and demographic attributes can influence how a professional chooses to engage in reciprocity, it is evident that without reciprocity, professional relationships in business will not exist (Llopis, 2016). If professionals can benefit each other through referrals, sales, contracts, and rewards, the power of reciprocity in action will be on full display within business communities, large and small. Reciprocal behavior is one that, when practiced, can yield positive results, but when used sparingly, can decay and become ineffective (Chuan et al., 2018) in fostering professional relationships. Gouldner (1960) first claimed that reciprocity is a universal personal norm; this research posits that professional reciprocity should now be considered a universal business norm due to the high interdependence on relational exchanges in building social capital.

\section{REFERENCES}

Abdul Malek, M.M., \& Jaguli, A.R. (2018). Generational differences in workplace communication: Perspectives of female leaders and their direct reports in Malaysia. Journal of Asian Pacific Communication (John Benjamins Publishing Co.), 28(1), 129-150. https://doi.org/10.1075/japc.00007.abd

Adler, P.S., \& Kwon, S-W. (2002). Social capital: Prospects for a new concept. Academy of Management Review, 27(1), 17-40. https://doi.org/10.5465/AMR.2002.5922314

Barney, J.B., \& Hansen, M.H. (1994). Trustworthiness as a source of competitive advantage. Strategic Management Journal, 15(S1), 175-190.

Belmi, P., \& Pfeffer, J. (2015). How "organization" can weaken the norm of reciprocity: The effects of attributions for favors and a calculative mindset. Academy of Management Discoveries, 1(1), 3657. https://doi.org/10.5465/amd.2014.0015

Budria, S., \& Ferrer-i-Carbonell, A. (2012). Income comparisons and non-cognitive skills. SSRN Electronic Journal. https://doi.org/10.2139/ssrn.2046976

Bowler, Wm.M., \& Brass, D.J. (2006). Relational correlates of interpersonal citizenship behavior: A social network perspective. Journal of Applied Psychology, 91(1), 70-82. https://doi.org/10.1037/0021-9010.91.1.70

Byron, K., \& Landis, B. (2020). Relational misperceptions in the workplace: New frontiers and challenges. Organization Science, 31(1), 223-242. https://doi.org/10.1287/orsc.2019.1285

Caliendo, M., Fossen, F., \& Kritikos, A. (2012). Trust, positive reciprocity, and negative reciprocity: Do these traits impact entrepreneurial dynamics? Journal of Economic Psychology, 33(2), 394-409.

Carpenter, M.A., \& Westphal, J.D. (2001). The strategic context of external network ties: Examining the impact of director appointments on board involvement in strategic decision making. Academy of Management Journal, 44(4), 639-660. https://doi.org/10.5465/3069408

Chollet, B., Géraudel, M., \& Mothe, C. (2014). Generating business referrals for SMEs: The contingent value of CEOs' social capital. Journal of Small Business Management, 52(1), 79-101. https://doi.org/10.1111/jsbm.12034

Chuan, A., Kessler, J.B., \& Milkman, K.L. (2018). Field study of charitable giving reveals that reciprocity decays over time. Proceedings of the National Academy of Sciences, 115(8), 17661771. https://doi.org/10.1073/pnas. 1708293115

Cropanzano, R., \& Mitchell, M. (2005). Social exchange theory: An interdisciplinary review. Journal of Management, 31(6), 874-900.

Dohmen, T., Falk, A., Huffman, D., \& Sunde, U. (2009). Homo reciprocans: Survey evidence on behavioural outcomes. The Economic Journal, 119(536), 592-612.

Eisenberger, R., Lynch, P., Aselage, J., \& Rohdieck, S. (2004). Who takes the most revenge? Individual differences in negative reciprocity norm endorsement. Personality and Social Psychology Bulletin, 30(6), 787-799. https://doi.org/10.1177/0146167204264047

Falk, A., \& Fischbacher, U. (2006). A theory of reciprocity. Games and Economic Behavior, 54(2), 293315. https://doi.org/10.1016/j.geb.2005.03.001 
Fitzgerald, C.J., \& Wickwire, J.H. (2012). Religion and political affiliation's influence on trust and reciprocity among strangers. Journal of Social, Evolutionary, and Cultural Psychology, 6(2), 158-180. https://doi.org/10.1037/h0099217

Gardiner, A.H. (1923). The eloquent peasant. The Journal of Egyptian Archaeology, 9(1/2), 5. https://doi.org/10.2307/3853490

Goldstein, N.J., Griskevicius, V., \& Cialdini, R.B. (2011). Reciprocity by proxy: A novel influence strategy for stimulating cooperation. Administrative Science Quarterly, 56(3), 441-473. https://doi.org/10.1177/0001839211435904

Gouldner, A.W. (1960). The norm of reciprocity: A preliminary statement. American Sociological Review, 25(2), 161. https://doi.org/10.2307/2092623

Haidt, J., \& Graham, J. (2007). When morality opposes justice: Conservatives have moral intuitions that liberals may not recognize. Social Justice Research, 20(1), 98-116. https://doi.org/10.1007/s11211-007-0034-z

Harris, R.D. (2017). The realm of supervision. Supervision, 78(10), 6.

Heider, F. (1958). The Psychology of Interpersonal Relations. John Wiley \& Sons.

Heineck, G., \& Anger, S. (2008). The returns to cognitive abilities and personality traits in Germany. SOEP Papers on Multidisciplinary Panel Data Research, 124.

Heyns, M.M., \& Kerr, M.D. (2018). Generational differences in workplace motivation. South African Journal of Human Resource Management, 16(1), N.PAG-N.PAG. https://doi.org/10.4102/sajhrm.v16i0.967

Knight, L., Hosegood, V., \& Timæus, I.M. (2016). Obligation to family during times of transition: Care, support and the response to HIV and AIDS in rural South Africa. AIDS Care, 28, 18-29. https://doi.org/10.1080/09540121.2016.1195486

Kolm, S.C. (1994). The theory of reciprocity and of the choice of economic systems: An introduction. Investigaciones Economicas, 18(1), 67-95.

Llopis, G. (2016, February 29). Relationships Without Reciprocity Are No Relationships at All. Forbes. Retrieved from https://www.forbes.com/sites/glennllopis/2016/02/29/relationships-withoutreciprocity-is-no-relationship-at-all/

Long, R.G., \& Mathews, K.M. (2011). Ethics in the family firm: Cohesion through reciprocity and exchange. Business Ethics Quarterly, 21(2), 287-308.

Mahmoodi, A., Bahrami, B., \& Mehring, C. (2018). Reciprocity of social influence. Nature Communications, 9(1), 2474. https://doi.org/10.1038/s41467-018-04925-y

Maximiano, S. (2012). Measuring reciprocity: Do survey and experimental data correlate? Krannert School of Management Working Paper.

Olk, P.M., \& Gibbons, D.E. (2010). Dynamics of Friendship Reciprocity Among Professional Adults. Journal of Applied Social Psychology, 40(5), 1146-1171. https://doi.org/10.1111/j.15591816.2010.00614.x

Oliveria, J.F. (2013). The Influence of the social capital on business performance: An analysis in the context of horizontal business networks. Revista de Administração Mackenzie, 14(3), 209-235.

Nahapiet, J., \& Ghoshal, S. (1998). Social capital, intellectual capital, and the organizational advantage. The Academy of Management Review, 23(2), 242-266.

Parette, P. (2005). Restrictiveness and race in special education: The issue of cultural reciprocity. Learning Disabilities-A Contemporary Journal, 3(1), 17-24.

Perugini, M., Gallucci, M., Presaghi, F., \& Ercolani, A.P. (2002). The personal norm of reciprocity. European Journal of Personality, 17(4), 251-283. https://doi.org/10.1002/per.474

Richter, D., Metzing, M., Weinhardt, M., \& Schupp, J. (2013). SOEP scales manual. SOEP Survey Papers 138: Series C., 78.

Sabel, C.F. (1993). Studied trust: Building new forms of cooperation in a volatile economy. Human Relations, 46(9), 1133-1170.

Sánchez-Franco, M.J., \& Roldán, J.L. (2015). The influence of familiarity, trust and norms of reciprocity on an experienced sense of community: An empirical analysis based on social online services.

102 Journal of Organizational Psychology Vol. 21(5) 2021 
Behaviour \& Information Technology, 34(4), 392-412.

https://doi.org/10.1080/0144929X.2014.959455

Sawilowsky, S.S. (2003). A different future for social and behavioral science research. Journal of Modern Applied Statistical Methods, 2(1), 128-132. https://doi.org/10.22237/jmasm/1051747860

Schweinfurth, M.K., \& Call, J. (2019). Reciprocity: Different behavioural strategies, cognitive mechanisms and psychological processes. Learning \& Behavior, 47(4), 284-301. https://doi.org/10.3758/s13420-019-00394-5

Tangpong, C., Li, J., \& Hung, K-T. (2016). Dark side of reciprocity norm: Ethical compromise in business exchanges. Industrial Marketing Management, 55, 83-96. https://doi.org/10.1016/j.indmarman.2016.02.015

Vaux Halliday, S. (2003). Which trust and when? Conceptualizing trust in business relationships based on context and contingency. The International Review of Retail, Distribution and Consumer Research, 13, 405-421. doi:10.1080/0959396032000129507

Villegas, S.G. (2020). Different yet similar: Multigenerational professionals and their sentimentality towards reciprocity. Journal of Business Diversity, 20(1), 66-79.

https://doi.org/10.33423/jbd.v20i1.2708 